\title{
Cytogenetic and Fluorescence in situ Hybridization Profile of Pediatric Acute Lymphoblastic Leukemia in a University Hospital in South India
}

\author{
Latha Sneha Magatha $^{a} \quad$ Julius Xavier Scott ${ }^{a} \quad$ Gayathri Subramaniam $^{b}$ \\ Thirugnanasambandan Chandrasekaran $^{a}$ Solomon Franklin Durairaj Paul ${ }^{b}$ \\ Teena Koshyb \\ aDivision of Pediatric Hemato-oncology, Department of Pediatrics, Sri Ramachandra Institute of Higher Education \\ and Research, Chennai, India; ' Department of Human Genetics, Sri Ramachandra Institute of Higher Education and \\ Research, Chennai, India
}

\section{Highlights of the Study}

- We report the frequency of cytogenetic abnormalities in children with acute lymphoblastic leukemia referred to a university hospital.

- In our study, $29.5 \%$ of the patients had chromosome anomalies and $46.4 \%$ had nonrandom abnormalities detected by interphase fluorescent in situ hybridization.

- Gain of RUNX1, KMT2A, and ETV6/RUNX1 fusion was observed in a significant number of patients.

\section{Keywords}

Pediatric acute lymphoblastic leukemia · Cytogenetics · $\mathrm{BCR} / \mathrm{ABL} 1 \cdot \mathrm{ETV} 6 / \mathrm{RUNX} 1 \cdot \mathrm{KMT} 2 \mathrm{~A}$ rearrangement $\cdot$

TCF3-PBX1

\begin{abstract}
Objective: The purpose of this study was to evaluate the cytogenetic and fluorescent in situ hybridization (FISH) profile in children with acute lymphoblastic leukemia (ALL), referred to a university hospital in a 5-year 6-month period. Subjects and Methods: Cytogenetic analysis of the bone marrow aspirate specimens of 91 patients was performed by standard Giemsa (G)-banding and interphase FISH (iFISH). Results: The frequency of chromosomal abnormalities detected by G-banding was $29.5 \%$, and the frequency of nonrandom abnormalities with independent prognostic significance identified by iFISH was $46.4 \%$. The abnormality with
\end{abstract}

karger@karger.com www.karger.com/mpp

Karger $\stackrel{\text { ' }}{5}$

BOPEN ACCESS
(C) 2021 The Author(s)

Published by S. Karger AG, Basel

This is an Open Access article licensed under the Creative Commons Attribution-NonCommercial-4.0 International License (CC BY-NC) (http://www.karger.com/Services/OpenAccessLicense), applicable to the online version of the article only. Usage and distribution for commercial purposes requires written permission. the highest frequency was gain of $R U N X 1$ ( $n=18,21.4 \%)$, followed by ETV6/RUNX1 fusion ( $n=7,8.3 \%)$, and gain of $K M$ $T 2 A(n=6,7.1 \%)$. Additionally, rarely reported gains of $E T V 6$, $P B X 1$, and $A B L 1$ were observed at a frequency of $6 \%(n=5)$, and the deletion of ETV6 and TCF3 was seen at a frequency of 3.6\% $(n=3)$ and $2.3 \%(n=2)$, respectively. A 10-year old with intrachromosomal amplification of chromosome 21 was also observed. Conclusions: This study strengthens and widens the current knowledge of the cytogenetic landscape of pediatric ALL.

(c) 2021 The Author(s)

Published by S. Karger AG, Basel

\section{Introduction}

Acute lymphoblastic leukemia (ALL) is the most frequent hematologic malignancy detected in the pediatric population and accounts for approximately $25 \%$ of can- 
cer diagnoses among children younger than 15 years of age $[1,2]$. This neoplasia is characterized by the abnormal proliferation of immature lymphoid cells, and the diagnosis is based on medical examination, flow cytometric immunophenotyping, cytochemical characteristics, and genetic findings [1].

In genetic analyses, conventional Giemsa (G)-banding is commonly used to detect chromosomal abnormalities in ALL [3]. However, this method has a few limitations; sometimes poor-quality chromosomes with indistinct banding for an accurate analysis are obtained, other times chromosomes may not be available for analysis and hence must be designated as a culture failure. Additionally, identification of certain subtle rearrangements, such as translocation of ETV6/RUNX1, is not possible, and this would require the application of interphase fluorescent in situ hybridization (iFISH) for detection $[4,5]$. Hence, chromosomal analysis with iFISH is more effective in diagnosing certain cryptic translocations [6]. In most countries, it has been established that genetic abnormalities can be identified in $75 \%-$ $80 \%$ of childhood ALL by standard chromosomal and iFISH analyses [2, 7]. Both these approaches group patients into favorable and unfavorable prognostic subgroups; the former includes hyperdiploidy and translocation ( $t$ ) $12 ; 21$ and the latter includes hypodiploidy, amplification of chromosome $21, t(9 ; 22)$, and KMT2A rearrangements.

Global studies also suggest that the frequency of genetic abnormalities in childhood ALL vary by ethnicity and the geographic region [8]. However, there remain limited figures from India; the reported data showing a higher proportion of children with unfavorable cytogenetics [9]. Since information on the cytogenetic profile among children belonging to south India is fairly scarce, it is still unclear whether these children present aberrations typically associated with poor or favorable prognoses more frequently than other ethnicities. The aim of this study was to report the chromosome abnormalities in cytogenetically evaluated pediatric patients with ALL, treated at a single university hospital in Chennai between October 2014 and April 2020.

\section{Materials and Methods}

This study was conducted in the Division of Pediatric HematoOncology, Department of Pediatrics in collaboration with the Department of Human Genetics, Sri Ramachandra Institute of Higher Education and Research (Chennai, India). All the patients younger than 18 years at the time of diagnosis and undergoing treatment for ALL were included in this study. Patients presenting with leukemia other than progenitor B-cell ALL were excluded.

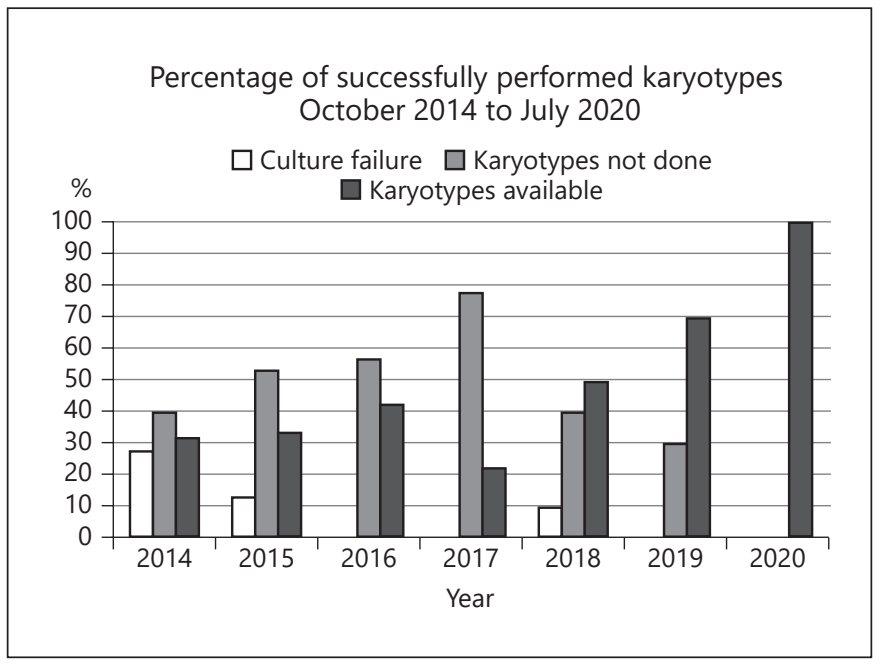

Fig. 1. Trend in percentage of successfully performed karyotyping.

For patients who had a relapse of ALL, only the findings at initial diagnosis were considered. The study was approved by the Institutional Ethics Committee (reference no: IEC-NI/14/JAN/38/03), and an informed assent was obtained from the parents.

Bone marrow aspiration was performed and processed for karyotyping by standard methods [10]. At least 10 metaphases were analyzed, and any numerical or structural chromosome abnormalities observed were reported in accordance with the ISCN 2020 [11]. FISH using commercial probes was performed as per the manufacturer's protocol and included the LSI ${ }^{\mathrm{TM}}$ ETV6/RUNX1 dual color (DC), dual fusion (DF) translocation probe, $\mathrm{LSI}^{\mathrm{TM}} \mathrm{BCR} /$ $A B L$ DC DF translocation, LSI ${ }^{\mathrm{TM}}$ TCF3/PBX1 DC DF translocation, and the LSI ${ }^{\mathrm{TM}} M L L \mathrm{DC}$, break apart rearrangement probes (Abbott Molecular, IL, USA). Analysis was conducted following the American College of Medical Genetics technical standards and guidelines for iFISH [12]. Two hundred interphase nuclei were scored for each probe by 2 independent analysts. If there were discrepant results, additional nuclei were examined by a third technologist. Probes were validated and cutoff values were determined in-house, before clinical use. To establish a FISH probe's limit of detection, the upper limit of the abnormal signal pattern in normal cells was calculated. Analysis of 200 nuclei, from at least 20 individuals who had no indication of having the condition of interest, was recorded. The normal cutoff value was calculated using the statistical method of confidence interval around the mean. A cutoff of $5 \%$ for abnormal signal pattern with a confidence limit of a $95 \%$ was considered acceptable for each FISH probe used.

Standard descriptive statistics was used to analyze the data. The categorized data were expressed as both number and percentage.

\section{Results}

In this 5.5-year period, a total of 91 patients underwent cytogenetic investigation, either chromosome analysis $(7.7 \%, n=7)$ or iFISH $(49.4 \%, n=45)$ alone or in combi- 
Table 1. Abnormal karyotypes were observed by G-banding in our series $(n=13)$

\begin{tabular}{llll}
\hline $\begin{array}{l}\text { Patient, } \\
n\end{array}$ & $\begin{array}{l}\text { Age, } \\
\text { years }\end{array}$ & Sex & Karyotype \\
\hline 1 & 17 & $\mathrm{M}$ & $92, \mathrm{XXYY}[10]$ \\
5 & 11 & $\mathrm{M}$ & $46, \mathrm{XY}, \operatorname{del}(11)(\mathrm{q} 13 \mathrm{q} 23)[10]$ \\
18 & 4 & $\mathrm{~F}$ & $45, \mathrm{XX},-7, \operatorname{add}(14)[10]$ \\
28 & 4 & $\mathrm{M}$ & $46, \mathrm{XY}, \operatorname{del}(9)(\mathrm{q} 12 \mathrm{q} 21)[4] / 46, \mathrm{XY}[13]$ \\
33 & 13 & $\mathrm{M}$ & $46, \mathrm{XY}, \mathrm{t}(9 ; 22)(\mathrm{q} 34 ; \mathrm{q} 11)[10]$ \\
34 & $5 \mathrm{mo}$ & $\mathrm{M}$ & $49, \mathrm{XY},+7,+8,+12[11] / 46, \mathrm{XY}[5]$ \\
45 & 14 & $\mathrm{~F}$ & $46, \mathrm{XY}, \operatorname{del}(9)(\mathrm{p} 12)[15]$ \\
50 & 4 & $\mathrm{M}$ & $58 \sim 61, \mathrm{XXY}, \mathrm{t}(1 ; 19)(\mathrm{q} 23 ; \mathrm{p} 13), \operatorname{del}(12)(\mathrm{p} 12),+2[10],+3[5],+4[11],+5[10],+6[11], 7[7],+8[7],+10[9],+1$ \\
& & & $1[9],+12[8],+13[5],+14[11],+15[6],+16[1],+17[11],+18[6],+21[12],+21[12],+21[2][\mathrm{cp} 12] / 46, \mathrm{XY}[8]$ \\
61 & 11 & $\mathrm{~F}$ & $45, \mathrm{X},-\mathrm{X}, \mathrm{t}(9 ; 12)(\mathrm{p} 24 ; \mathrm{q} 21), \mathrm{t}(12 ; 17)(\mathrm{p} 13 ; \mathrm{q} 12)[10] / 44, \mathrm{X},-\mathrm{X}, \mathrm{t}(9 ; 12)(\mathrm{p} 24 ; \mathrm{q} 21), \mathrm{t}(12 ; 17)(\mathrm{p} 13 ; \mathrm{q} 12),-22[6]$ \\
64 & 4 & $\mathrm{~F}$ & $46, \mathrm{XX}, \mathrm{add}(12)(\mathrm{p} 13)[5] / 46, \mathrm{XX}[7]$ \\
74 & 3 & $\mathrm{~F}$ & $52 \sim 55, \mathrm{XX}[10]$ \\
89 & 1 & $\mathrm{~F}$ & $45, \mathrm{XX}, \operatorname{dic}(7 ; 9)(\mathrm{p} 11 ; \mathrm{p} 11), \operatorname{der}(8) ? \mathrm{t}(7 ; 8)(\mathrm{p} 12-22 ; \mathrm{p} 21)[20]$ \\
91 & & $\mathrm{M}$ & $42-56, \mathrm{XY}[3] / 46, \mathrm{XY}[17]$ \\
\hline
\end{tabular}

G, Giemsa.

nation $(42.9 \%, n=39)$. The mean age of patients at the time of diagnosis was $6.8 \pm 4.7$ years, with the minimum age at diagnosis being 5 months and the maximum 17 years. Sixty-four patients $(70.3 \%)$ were below the age of 10 years and $27(29.7 \%)$ were above the age of 10 years. A majority of the patients were males $(65 \%, n=59)$. While the total leukocyte count at diagnosis ranged from 1,500/ $\mathrm{mm}^{3}$ to $1,91,200 / \mathrm{mm}^{3}$, the platelet count ranged from $12,000 / \mu \mathrm{L}$ to $5,00,000 / \mu \mathrm{L}$.

The percentage of successfully performed karyotyping improved progressively, with a success rate of $31.3 \%(n=$ 10 of 32$)$ in $2014,69.2 \%(n=3$ of 4$)$ in 2019 , and $100 \%$ ( $n=5$ of 5) by 2020 (Fig. 1). This is credited to the modifications in processing methods to optimize the results. The use of FISH, introduced in our laboratory in 2014, was very useful to detect cryptic rearrangements and was used as an alternate test in cases where metaphase chromosomes were not obtained for analysis (culture failure). Using this approach, we were able to improve our reporting rate from $50 \%(n=9$ of 18$)$ in 2014 to $87.5 \%$ ( $n=6$ of 7 ) in 2016 and $100 \%$ by 2020 ( $n=5$ of 5$)$.

\section{Cytogenetic Profile}

Karyotyping was performed in 46 patients at diagnosis and was successful in 44 patients (95.6\%). An abnormal chromosome study was observed in 13 patients (29.5\%). Low hypodiploidy, defined with the modal number 3338 and near haploidy (modal number 24-29), was not observed in this study population. Karyotypes with structural abnormalities, either isolated or in combination
Table 2. Frequency of abnormalities detected by iFISH $(n=84)$

\begin{tabular}{lccc}
\hline Loci & $\begin{array}{l}\text { Frequency, } \\
n(\%)\end{array}$ & $\begin{array}{l}\text { Sex, } \\
\mathrm{M} / \mathrm{F}\end{array}$ & $\begin{array}{l}\text { Median } \\
\text { age, years }\end{array}$ \\
\hline $\begin{array}{l}\text { Fusions/rearrangements } \\
\text { ETV6/RUNX1 }\end{array}$ & $7(8.3)$ & $3 / 4$ & 4 \\
BCR/ABL1 & $4(4.8)$ & $4 / 0$ & 9.5 \\
KMT2A & $3(3.5)$ & $2 / 1$ & 11 \\
TCF3/PBX1 & $3(3.5)$ & $0 / 3$ & 2 \\
Loss/deletion & & & \\
ETV6 & $3(3.6)$ & $1 / 2$ & 4 \\
TCF3 & $2(2.3)$ & $2 / 0$ & 4 \\
Gain & & & \\
RUNX1 & $18(21.4)$ & $12 / 6$ & 3.5 \\
KMT2A & $6(7.1)$ & $6 / 0$ & 4.5 \\
ETV6 & $5(6.0)$ & $3 / 2$ & 3 \\
PBX1 & $5(6.0)$ & $4 / 1$ & 4 \\
\hline
\end{tabular}

iFISH, interphase fluorescent in situ hybridization.

with numerical abnormalities/ploidy, observed by Gbanding are summarized in Table 1.

\section{Interphase Fluorescent in situ Hybridization}

iFISH was performed for 84 patients (92.3\%), and nonrandom abnormalities were observed in 39 patients (46.4\%). Table 2 describes the frequency of these abnormalities detected by iFISH. Gains and losses of the targeted loci were observed, either as isolated findings or in combination with the fusion/rearrangements. Of the 
Table 3. Distribution of cytogenetic and iFISH findings $(n=39)$

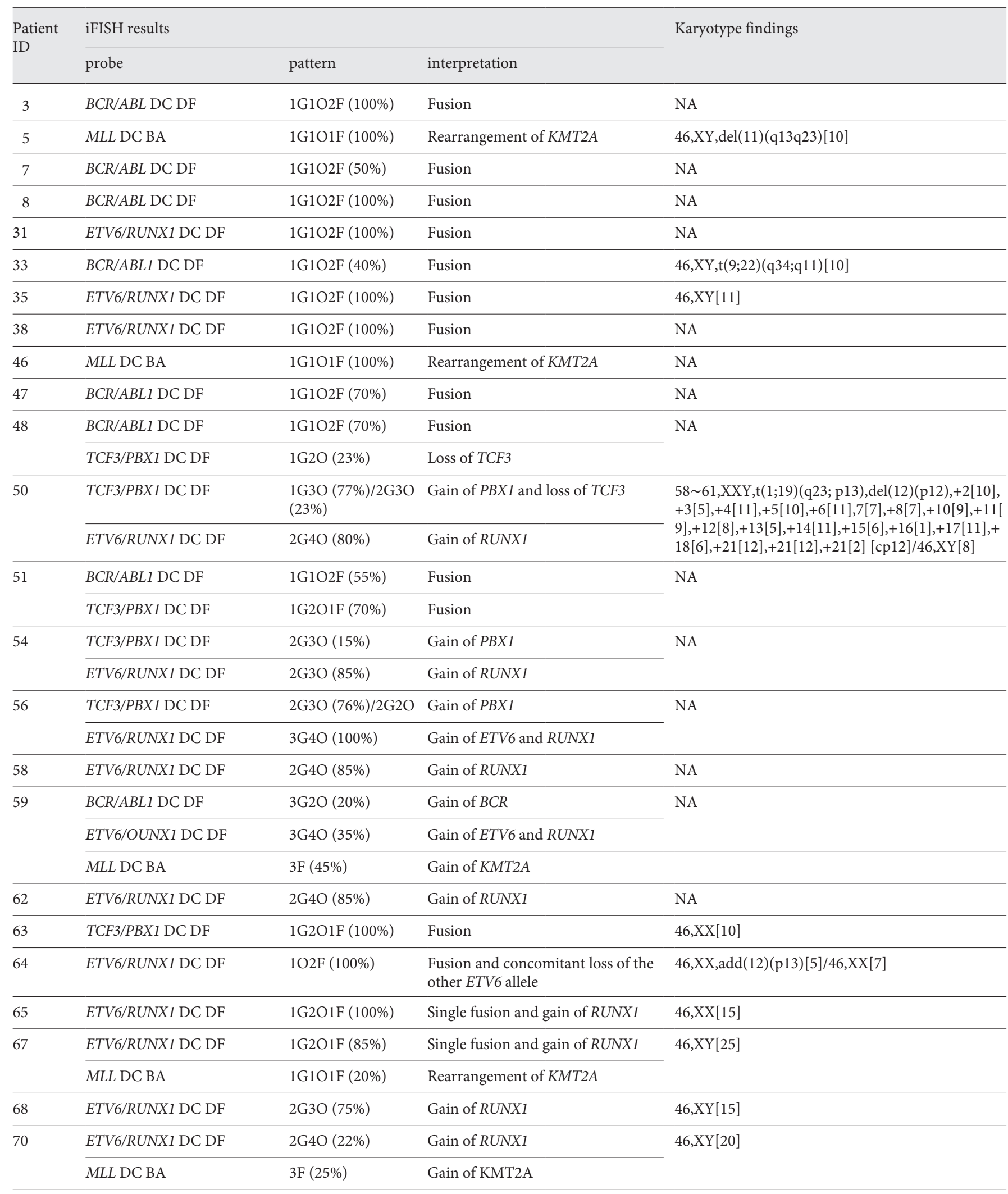


Table 3 (continued)

\begin{tabular}{|c|c|c|c|c|}
\hline \multirow{2}{*}{$\begin{array}{l}\text { Patient } \\
\text { ID }\end{array}$} & \multicolumn{3}{|l|}{ iFISH results } & \multirow[t]{2}{*}{ Karyotype findings } \\
\hline & probe & pattern & interpretation & \\
\hline \multirow[t]{2}{*}{72} & $B C R / A B L 1 \mathrm{DC} \mathrm{DF}$ & $2 \mathrm{G} 3 \mathrm{O}(65 \%)$ & Gain of $A B L 1$ & \multirow[t]{2}{*}{$46, \mathrm{XY}[12]$} \\
\hline & ETV6/RUNX1 DC DF & $2 \mathrm{G} 4 \mathrm{O}(68 \%)$ & Gain of RUNX1 & \\
\hline 73 & $B C R / A B L 1 \mathrm{DC} D F$ & $2 \mathrm{G} 3 \mathrm{O}(45 \%)$ & Gain of $A B L 1$ & $46, \mathrm{XY}[20]$ \\
\hline 74 & ETV6/RUNX1 DC DF & $2 \mathrm{G} 4 \mathrm{O}(100 \%)$ & Gain of RUNX1 & $52 \sim 55, \mathrm{XX}[10]$ \\
\hline 75 & ETV6/RUNX1 DC DF & $2 \mathrm{G} 3 \mathrm{O}(66 \%)$ & Gain of RUNX1 & $46, \mathrm{XY}[11]$ \\
\hline 76 & $B C R / A B L 1 \mathrm{DC} D F$ & $2 \mathrm{G} 3 \mathrm{O}(25 \%)$ & Gain of $A B L 1$ & NA \\
\hline \multirow{2}{*}{77} & $M L L \mathrm{DC} B \mathrm{BA}$ & $3 \mathrm{~F}(80 \%)$ & Gain of $K M T 2 A$ & \multirow{2}{*}{$46, \mathrm{XY}[11]$} \\
\hline & TCF3/PBX1 DC DF & $2 \mathrm{G} 3 \mathrm{O}(80 \%)$ & Gain of $P B X 1$ & \\
\hline \multirow[t]{3}{*}{78} & $B C R / A B L 1 \mathrm{DC} D F$ & $3 \mathrm{G} 2 \mathrm{O}(40 \%)$ & Gain of $B C R$ & \multirow[t]{3}{*}{ NA } \\
\hline & ETV6/RUNX1 DC DF & $2 \mathrm{G} 4 \mathrm{O}(35 \%)$ & Gain of RUNX1 & \\
\hline & $M L L \mathrm{DC} \mathrm{BA}$ & $3 \mathrm{~F}(25 \%)$ & Gain of $K M T 2 A$ & \\
\hline 79 & $T C F 3 / P B X 1 \mathrm{DC} D F$ & $3 \mathrm{G} 2 \mathrm{O}(57 \%)$ & Gain of TCF3 & NA \\
\hline 81 & ETV6/RUNX1 DC DF & $1 \mathrm{G} 2 \mathrm{O} 1 \mathrm{~F}(100 \%)$ & Single fusion and gain of $R U N X 1$ & $46, \mathrm{XY}[20]$ \\
\hline 82 & ETV6/RUNX1 DC DF & $1 \mathrm{G} 7 \mathrm{O}(100 \%)$ & iAMP21 & NA \\
\hline
\end{tabular}

BA, break apart; DC, dual color; DF, dual fusion; F, fusion; G, spectrum green; iAMP21, intrachromosomal amplification of chromosome 21; O, spectrum orange; iFISH, interphase fluorescent in situ hybridization.

21 patients detected with gains of RUNX1, KMT2A, ETV6, $P B X 1$, and TCF3 (either isolated or in combination), 10 of them had a normal karyotype with no cells showing high hyperdiploidy (HHD). While for 9 patients, a karyotype was not available and HHD could not be confirmed, for 2 patients, HHD was observed. Also, as per the guidelines of Harrison et al. [13] patient \# 82 was classified as intrachromosomal amplification of chromosome 21 (iAMP21) using the established criteria of 3 or more additional RUNX1 signals ( 5 or more signals per cell in total) with a FISH probe targeting the RUNX1 gene.

Cytogenetic Profile in Pediatric Acute Lymphoblastic Leukemia
Among the fusions, the translocation of chromosomes 12 and 21, ETV6/RUNX1 fusion, was the most frequent rearrangement found in our series. The expected iFISH signal pattern of $\mathrm{t}(12 ; 21)(\mathrm{p} 13 ; \mathrm{q} 22)$ translocation consists of 1 orange (RUNX1), 1 green (ETV6), and 2 fusions (der [12] and der [21]). It was detected in 7 patients (8.3\%), identified solely by iFISH. In addition to having the ETV6/ RUNX1 fusion, 1 patient had an abnormality in the short arm of chromosome 12 with additional chromosome material of unknown origin present on the $\mathrm{p}$ arm. A high frequency $(4.8 \%, n=4)$ of the translocation of chromosomes 9 and 22 (BCR-ABL1 fusion) was also seen; 1 patient by 
iFISH and G-banding and in 3 patients by iFISH alone. In a nucleus containing a simple balanced $t(9 ; 22), 1$ orange and 1 green signal from the normal 9 and 22 chromosomes and 2 orange/green (yellow) fusion signals, one each from the derivative 9 and 22 chromosomes, will be observed (1O1G2F). Gain of the BCR and ABL1 loci, seen as either an ES (extra green or orange) signal pattern, was observed in 3 (3.6\%) and $5(6 \%)$ patients, respectively.

Abnormalities of the $11 \mathrm{q} 23$ region involving the $K M$ T2A gene were detected in 3 patients $(3.3 \%)$ by iFISH alone. Interphase nuclei with one fusion signal and one separate orange and green signal (1G1R1F) represents a translocation with KTM2A involvement. One patient with this rearrangement also had a deletion in the long arm of chromosome 11, possibly the one not involved in the rearrangement.

TCF3-PBX1 fusion or $\mathrm{t}(1 ; 19)(\mathrm{q} 23 ; \mathrm{p} 13.3)$ by iFISH was detected in 3 patients (3.5\%). Abnormal hybridization would result in 1 green, 1 orange, and 2 fusion (1G102F) signals. One patient ( $\# 50)$, in whom the translocation was detected in the karyotype, had an atypical iFISH signal pattern interpreted as gain of $P B X 1$ and loss of TCF3. The distribution of the abnormal cytogenetic and iFISH findings is summarized in Table 3.

\section{Discussion}

Fifty-five to eighty-nine percent of pediatric patients with ALL have chromosome abnormalities detected by conventional cytogenetics and FISH; the varying percentage is dependent on the number of patients studied, the year they were reported, and the populations where they have been studied [14-19]. As established in these studies, to improve the survival of children with ALL, it is important to evaluate the cytogenetic profile. We report the cytogenetic findings in 91 children with ALL spanning a period of 5 years and 6 months referred to our university hospital located in south India.

The frequency of the $B C R / A B L 1$ positive cases at $4.8 \%$ $(n=4)$ was similar to that observed in other populations reporting 5-10\% [20], highlighting the fact that analysis of this fusion transcript should be mandatory in all cases of ALL as these patients may benefit from the addition of tyrosine kinase inhibitors. The frequency of ETV6/ RUNX1 at $8.3 \%(n=7)$ was higher than that observed in 2 studies from India reporting a frequency of $4.3 \%-7.3 \%$ $[21,22]$. A worldwide variation in the incidence of ETV6/ RUNX1 fusion has been reported with the frequency ranging from 13 to $25 \%$ [23]. KMT2A gene rearrange- ments are associated with a poor prognosis and are generally seen in infants $<1$ year of age [22]. In contrast, in this study, KMT2A rearrangement was detected in 3 patients (3.5\%) aged 2, 11, and 14 years. Previous studies in India have reported either an absence of this transcript or a low frequency ranging from $1.5 \%$ to $3.1 \%$ [22].

FISH analysis is used in many laboratories to confirm the presence of previously characterized chromosome abnormalities or to rule out suspected cryptic aberrations, thus compensating the shortcomings of karyotyping including culture failure. In cases where we failed to obtain metaphases for analysis, iFISH allowed us to screen large numbers of nondividing cells. In addition, with the inclusion of FISH we were also able to detect losses and gain of loci targeted by the FISH probes.

Similar to our findings, Harewood et al. [24] reported clusters of RUNX1 signals visible at interphase by FISH in the largest series of 20 ALL patients. However, compared to their patient series, ours differed in 2 factors; the karyotypes in all but one were normal, and the median age of our patient series was younger, 3.5 years compared to their 9 years. Mikhail et al. [25] had a study population that appeared similar to our series in that they were all 6 years old or less and karyotypes were normal in 3 of them, even though one harbored at $(12 ; 21)$ translocation. These authors also demonstrated that the detection of extra $R U N X 1$ signals by FISH was associated with overexpression of RUNX1 measured by real-time quantitative RTPCR. Since we did not include RT-PCR in our investigations we cannot confirm that is applicable to our patients. Of interest was one of the patients (\#82) with 7 signals for $R U N X 1$ which was interpreted as iAMP21 as per the guidelines of Harrison et al. [26]. iAMP21 is defined as gain of at least 3 copies of part of chromosome 21 incorporating RUNX1 [2], (5 or more signals per cell in total) with a FISH probe targeting the RUNX1 [26]. However, it is of interest to consider whether amplification within a single chromosome has the same effect as an acquired gain of chromosome 21, and to what extent the structure and expression of the gene are altered in these different situations and directly contributes to the etiology of ALL.

KMT2A rearrangement most often results from translocation or partial tandem duplication, although recent published reports suggest a different mechanism by which KMT2A might participate in leukemogenesis, $K M$ $T 2 A$ amplification [27]. Homogeneously staining regions or ring chromosomes are the most common manifestations of gain/amplification seen in a karyotype, which we did not observe in our 2 patients. Gain of KMT2A and/or amplifications have been reported primarily in myeloid 
malignancies, therapy-related acute myeloid leukemia, or myelodysplasia [28]. In this context, our findings in Blineage ALLs seem noteworthy. The same could be said for the $A B L 1$ gene, which was the next most frequent gain seen in our patient series. The presence of just one extra signal for $A B L 1$ and $B C R$ seen in 5 and 3 patients, respectively, was interpreted as gain of these loci. However, to the best of our knowledge, there have been limited reports of such findings in pediatric ALL. Considering that there was no visible evidence of double minutes in the available karyotype, it would be worthwhile to characterize these findings with molecular techniques like microarray.

The deletion of the normal ETV6 allele was detected in 2 patients with the ETV6/RUNX1 gene fusion and 1 patient with a normal karyotype. Raynaud et al. [29] indicated that the association between the $t(12 ; 21)$ and the deletion of the nontranslocated allele of ETV6 is among the most frequent abnormalities observed in B-lineage ALLs and provides a further proliferative advantage to leukemic cells. However, there are limited reports of gain of ETV6, TCF3 deletion, or gain of PBX1 with ALL. Thus, this could be unique findings in our population and warrants exploration in a larger patient series.

\section{Conclusion}

There still exists a need to address racial and ethnic gaps in the cytogenetic profile of childhood ALL, the most common pediatric cancer. In this study, though the number of patients tested was small, our findings are comparable to other studies and, more importantly, add to the limited data from India.

\section{Acknowledgment}

The authors would like to thank the study participants and the parents for permitting us to include their data.

\section{Statement of Ethics}

The parents of the subjects gave their written informed consent and that the study protocol was approved by the Institute's Committee on Human Research (reference no: IEC-NI/14/JAN/38/03).

\section{Conflict of Interest Statement}

The authors have no conflicts of interest to declare.

\section{Funding Sources}

This work was funded by Sri Ramachandra Institute of Higher Education and Research through intramural funding (GATE).

\section{Author Contributions}

Latha Sneha Magatha, Julius Xavier Scott, and Thirugnanasambandan Chandrasekaran performed clinical investigations, shared clinical data, and wrote clinical parts of the manuscript. Gayathri Subramaniam, Solomon Franklin Durairaj Paul, and Teena Koshy performed the cytogenetic and iFISH investigations and compiled the data. Teena Koshy drafted the manuscript. All authors read and approved the final manuscript.

\section{Data Availability Statement}

The datasets generated during and/or analysed during the current study are available from the corresponding author on reasonable request.

\section{References}

1 PDQ Pediatric Treatment Editorial Board. Childhood acute lymphoblastic leukemia treatment $\left(\mathrm{PDQ}^{\circ}\right)$ : health professional version. In: PDQ cancer information summaries. Bethesda (MD): National Cancer Institute (US); 2020.

2 Hunger SP, Mullighan CG. Redefining ALL classification: toward detecting high-risk ALL and implementing precision medicine. Blood. 2015;125(26):3977-87.

3 Chang HH, Lu MY, Jou ST, Lin KH, Tien HF, Lin DT. Cytogenetics in childhood acute lymphoblastic leukemia in Taiwan: a single-institutional experience. Pediatr Hematol Oncol. 2006;23(6):495-506.

4 Romana SP, Coniat ML, Berger RT. t(12; 21): a new recurrent translocation in acute lymphoblastic leukemia. Genes Chromosomes Cancer. 1994;9(3):186-91.
5 Spathas DH, Stewart J, Singer IO, Theriault A, Bovey M, Connor JM. Detection of $\mathrm{t}$ (12; 21 ) in childhood acute lymphoblastic leukemia by fluorescence in situ hybridization. Cancer Genetics Cytogenetics. 1999;110(1): 7-13.

6 Nordgren A, Heyman M, Sahlén S, Schoumans J, Söderhäll S, Nordenskjöld M, et al. Spectral karyotyping and interphase FISH reveal abnormalities not detected by conventional G-banding: implications for treatment stratification of childhood acute lymphoblastic leukaemia: detailed analysis of 70 cases. Eur J Haematol. 2002;68(1):31-41.

7 Pui CH, Carroll WL, Meshinchi S, Arceci RJ. Biology, risk stratification, and therapy of pediatric acute leukemias: an update. J Clin Oncol. 2011;29(5):551.
8 Lim JY, Bhatia S, Robison LL, Yang JJ. Genomics of racial and ethnic disparities in childhood acute lymphoblastic leukemia. Cancer. 2014;120(7):955-62.

9 Advani S, Pai S, Venzon D, Adde M, Kurkure PK, Nair CN, et al. Acute lymphoblastic leukemia in India: an analysis of prognostic factors using a single treatment regimen. Ann Oncol. 1999;10(2):167-76.

10 Arsham MS, Barch MJ, Lawce HJ, editors. The AGT cytogenetics laboratory manual. John Wiley \& Sons; 2017.

11 McGowan-Jordan J, Simons A, Schmid M, editors. Recommendations of the International Standing Committee on Human Cytogenetic Nomenclature Including New Sequence-based Cytogenomic Nomenclature. Karger; 2016. 
12 Mascarello JT, Hirsch B, Kearney HM, Ketterling RP, Olson SB, Quigley DI, et al. Section E9 of the American College of Medical Genetics technical standards and guidelines: fluorescence in situ hybridization. Genet Med. 2011;13(7):667-75.

13 Harrison CJ, Moorman AV, Schwab C, Carroll AJ, Raetz EA, Devidas M, et al. An international study of intrachromosomal amplification of chromosome 21 (iAMP21): cytogenetic characterization and outcome. Leukemia. 2014;28(5):1015-21.

14 Chessels JM, Swansbury GJ, Reeves B, Bailey CC, Richards SM. Medical Research Council Working Party in Childhood Leukaemia. Cytogenetics and prognosis in childhood lymphoblastic leukaemia: results of MRC UKALL X. Bri J Haematol. 1997;99:93-100.

15 Andreasson P, Höglund M, Békássy AN, Garwicz S, Heldrup J, Mitelman F, et al. Cytogenetic and FISH studies of a single center consecutive series of 152 childhood acute lymphoblastic leukemias. Eur J Haematol. 2000; 65(1):40-51.

16 Forestier E, Johansson B, Borgström G, Kerndrup G, Johansson J, Heim S, et al. Cytogenetic findings in a population-based series of 787 childhood acute lymphoblastic leukemias from the Nordic countries. The NOPHO Leukemia Cytogenetic Study Group. Eur J Haematol. 2000;64(3):194-200.

17 De Braekeleer E, Basinko A, Douet-Guilbert $\mathrm{N}$, Morel F, Le Bris MJ, Berthou C, et al. Cytogenetics in pre-B and B-cell acute lymphoblastic leukemia: a study of 208 patients diagnosed between 1981 and 2008. Cancer Genet Cytogenet. 2010;200(1):8-15.
18 Moorman AV, Ensor HM, Richards SM, Chilton L, Schwab C, Kinsey SE, et al. Prognostic effect of chromosomal abnormalities in childhood B-cell precursor acute lymphoblastic leukaemia: results from the UK Medical Research Council ALL97/99 randomised trial. Lancet Oncol. 2010;11(5):429-38.

19 Gil EA, Lajus TB, de Moura TM, Freire JM, da Fernandes AL, Leão GD, et al. Banding cytogenetic analysis in pediatric patients with acute lymphoblastic leukemia (ALL) in a Brazilian population. Mol Cytogenet. 2013;6(1): $37-6$.

20 Arana-Trejo RM, Ignacio G, Amador-Sánchez R, Cruz-Rico J, Hernández M-P, Saldivar I, et al. Frequency of p190 and p210 BCR-ABL fusions genes in acute lymphoblastic leukemia in a long group of adults and childhood. Blood. 2016;128(22):5273.

21 Mazloumi SH, Madhumathi DS, Appaji L, Prasannakumari P. Combined study of cytogenetics and fluorescence in situ hybridization (FISH) analysis in childhood acute lymphoblastic leukemia (ALL) in a tertiary cancer centre in South India. Asian Pac J Cancer Prev. 2012;13(8):3825-7.

22 Chopra A, Soni S, Verma D, Kumar D, Dwivedi R, Vishwanathan A, et al. Prevalence of common fusion transcripts in acute lymphoblastic leukemia: a report of 304 cases. Asia Pac J Clin Oncol. 2015;11(4):293-8.

23 Yehuda-Gafni O, Cividalli G, Abrahmov A, Weintrob M, Neriah SB, Cohen R, et al. Fluorescence in situ hybridization analysis of the cryptic $\mathrm{t}(12 ; 21)(\mathrm{p} 13 ; \mathrm{q} 22)$ in childhood B-lineage acute lymphoblastic leukemia. Cancer Genet Cytogenet. 2002;132(1):61-4.
24 Harewood L, Robinson H, Harris R, Al-Obaidi MJ, Jalali GR, Martineau M, et al. Amplification of AML1 on a duplicated chromosome 21 in acute lymphoblastic leukemia: a study of 20 cases. Leukemia. 2003;17(3):547-53.

25 Mikhail FM, Serry KA, Hatem N, Mourad ZI, Farawela HM, El Kaffash DM, et al. AML1 gene over-expression in childhood acute lymphoblastic leukemia. Leukemia. 2002;16(4): 658-68.

26 Harrison CJ, Moorman AV, Barber KE, Broadfield ZJ, Cheung KL, Harris RL, et al. Interphase molecular cytogenetic screening for chromosomal abnormalities of prognostic significance in childhood acute lymphoblastic leukaemia: a UK Cancer Cytogenetics Group Study. Br J Haematol. 2005;129(4):520-30.

27 Dolan M, McGlennen RC, Hirsch B. MLL amplification in myeloid malignancies: clini$\mathrm{cal}$, molecular, and cytogenetic findings. Cancer Genet Cytogenet. 2002;134(2):93-101.

28 Racke F, Cole C, Walker A, Jones J, Heerema NA. Therapy-related pro-B cell acute lymphoblastic leukemia: report of two patients with MLL amplification. Cancer Genet. 2012; 205(12):653-6.

29 Raynaud S, Cave H, Baens M, Bastard C, Cacheux V, Grosgeorge J, et al. The 12; 21 translocation involving TEL and deletion of the other TEL allele: two frequently associated alterations found in childhood acute lymphoblastic leukemia. Blood. 1996;87 (7):2891-9. 